\title{
PENTINGNYA ADMINISTRASI KEPENDUDUKAN TERKAIT SENSUS PEN- DUDUK SECARA ONE LINE 2020 DI DESA PERTIMA KECAMATAN KARAN- GASEM KABUPATEN KARANGASEM
}

\author{
Ni Wayan Sutiani \\ Fakultas Ilmu Sosial dan Ilmu Politik Universitas Mahendradatta Denpasar \\ E-mail: sutianiwayan42@gmail.com
}

\begin{abstract}
Abstrak - Sensus penduduk menjadi momen penting terwujudnya penyatuan data dari data registrasi yang dihasilkan oleh Dinas Kependudukan dan Catatan Sipil dan data hasil proyeksi dari Badan Pusat Statistik. Berdasarkan uraian di atas, dapat dirumuskan permasalahan sebagai berikut: Bagaimakah Pentingnya Administrasi Kependudukan Terkait Sensus Penduduk Secara One Line di Desa Pertima Kecamatan Karangasem Kabupaten Karangasem? Apa saja kendala dan upaya pelaksanaan sensus online di Desa Pertima Kecamatan Karangasem Kabupaen Karangasem?. Pada penelitian ini, metode penelitian yang dilakukan adalah dengan wawancara, studi kepustakaan dengan membaca literatur yang berkaitan dengan sensus penduduk, observasi dan penelitian lapangan, dimana penelitian dilakukan dengan terjun langsung ke Desa Pertima. Hasil penelitian menunjukkan bahwa administrasi kependudukan secara online sangat penting, yakni: menyediakan data jumlah, komposisi, distribusi, dan karakteristik penduduk Desa Pertima menurut de facto dan de jure menuju Satu Data Kependudukan Indonesia. Kedua, yakni menyediakan parameter demografi dan proyeksi penduduk (fertilitas, mortalitas, dan migrasi), serta karakteristik penduduk lainnya untuk keperluan proyeksi penduduk dan berbagai indikator Target Pembangunan Berkelanjutan (SDGs). Adapun kendala yang dihadapi dalam pendataan penduduk adalah sulitnya login sensus penduduk secara online, kendala jaringan internet, masyarakat yang masih awam teknologi. Untuk mengatasi dilakukan dengan memberi sosialisasi kepada aparat desa agar bisa memandu warganya untuk sensus secara online. Memanfaatkan handphone yang mempunyai fasilitas androi sehingga bisa mengakses internet dengan cept.
\end{abstract}

Kata Kunci: Administrasi, kependudukan, sensus penduduk online

\begin{abstract}
Population census is an important moment of the realization of the unification of data from registration data generated by the Population and Civil Registry Office and projection data from the Central Statistics Agency. Based on the description above, the following problems can be formulated: How Important is the Population Administration Regarding One Line Population Census in Pertima Village, Karangasem District, Karangasem Regency? What are the obstacles and efforts to implement an online census in Pertima Village, Karangasem District, Karangasem Regency? In this study, the research method used was interviews, literature study by reading literature related to population censuses, observations and field research, where research was conducted by jumping directly into Pertima Village. The results showed that online population administration is very important, namely: providing data on the number, composition, distribution, and characteristics of Pertima Village residents according to de facto and de jure towards the Indonesian Population Data. Second, namely providing demographic parameters and population projections (fertility, mortality, and migration), as well as other population characteristics for the purposes of population projection and various indicators of Sustainable Development Targets (SDGs). The obstacle faced in population data collection is the difficulty of logging online population censuses, internet network constraints, people who are still technologically unfamiliar. To overcome this problem is done by giving socialization to village officials so that they can guide their citizens to the online census. Utilizing a cellphone that has Androi facilities so that it can access the internet with speed.
\end{abstract}

Keywords: Population administration, online population census 


\section{Pendahuluan}

Rapat Koordinasi Pelaksanaan Sensus Penduduk, berbasis online tahun 2020 untuk Kabupaten Karangasem berlangsung di Wantilan Kantor Bupati Karangasem, Senin (10/2). Rapat Koordinasi ini diselenggarakan oleh Badan Pusat Statistik dalam rangka menjaring masukan sekaligus menyosialisasikan Sensus Penduduk Berbasis online yang diselenggarakan tahun 2020 ini.

Bupati Mas Sumatri dalam sambutannya mengatakan, pertemuan hari ini merupakan pertemuan yang sangat baik untuk dilaksanakan dalam rangka 'membangun kordinasi untuk bersama-sama menyukseskan Sensus Penduduk 2020. Sensus Penduduk 2020 merupakan Langkah menuju Satu Data Kependudukan, yang nantinya juga akan mengarah pada terwujudnya Satu Data Indonesia.

Sensus penduduk menjadi momen penting terwujudnya penyatuan data dari data registrasi yang dihasilkan oleh Dinas Kependudukan dan Catatan Sipil dan data hasil proyeksi dari Badan Pusat Statistik. Seperti diketahui saat ini ada dua data yang umum digunakan, dengan perbedaan yang cukup jauh. Terlepas dari perbedaan yang ada, tidak hendak membahas data yang mana yang benar dan mana yang salah, namun untuk berkerja sama membangun data penduduk, berangkat dari menyukseskan Sensus Penduduk 2020.

Sensus Penduduk menjadi istimewa tidak hanya karena menggunakan basis data registrasi, namun juga akan menghasilkan data penduduk baik secara de facto maupun de jure. Dari Sensus ini nantinya akan bisa diperoleh berapa jumlah penduduk yang benar-benar tinggal di Karangasem baik berKTP Karangasem maupun tidak. Demikian halnya jumlah penduduk ber-KTP Karangasem yang tinggal di luar Kabupaten Karangasem. Dengan pilihan ini, tentunya akanlebih mempertajam program dan kebijakan pembangunan ke depan. Di samping itu, padaSensus Penduduk nanti juga sudah akan memanfaatkan teknologi informasi. Sensus Penduduk bisa dilakukan secara online. Masyarakat secara mandiri melakukan pengecekan dan pembaharuan identitas kependudukannya kapan saja dan di mana saja, baik melalui HP maupun komputer, yang penting terhubung den- gan internet. Dengan kondisi ini tentunya kualitas data penduduk nantinya terletak pada partisipasi kita semua dengan memberikan jawaban yang akurat pada Sensus Penduduk nanti.

Kondisi geografis dan tingkat kesadaran serta pendidikan masyarakat akan menjadi kendala dalam hal ini. Paling tidak seluruh ASN dan tenaga kontrak di lingkungan Pemerintah Kabupaten Karangasem melaksanakan Sensus Penduduk secara on-line. Selanjutnya, dapat mengajak sanak keluarga, kerabat, dan teman-temannya untuk ikut serta. Dukungan untuk Sensus Penduduk ini dapat dilakukan dengan menyebarluaskan informasi mengenai SP2020 di berbagai kesempatan dan media, termasuk Whatsapp Group. Bagi institusi/OPD yang memiliki jaringan yang banyak, dapat membuat surat edaran yang menjangkau anggotanya sampai tingkat terbawah. Penggunaan teknologi informasi dalam Sensus Penduduk 2020 merupakan hal yang baru. Tidak menutup kemungkinan banyak kendala yang akan ditemui, baik dari kesiapan sistem, jaringan mupun kendala Iainnya.

"Namun demikian saya harap untuk tidak langsung menyerah. Saya yakin BPS pasti sudah menyiapkan berbagai antisipasi untuk itu. Mari kita bersama-sama berkolaborasi membangun Karangasem dimulai dari membangun data kependudukan yang Iebih baik. Mari kita tunjukkan bahwa Karangasem juga mampu dan siap mengadopsi perkembangan teknologi.

Menuurut BPS, Sensus Penduduk2020 akan dilaksanakan dalam dua tahap. Pertama, adalah Sensus Penduduk online. Yaitu, seluruh penduduk Indonesia secara aktif mengisikan data kependudukannya secara mandiri melalui link sensus.bps.go.id/cek dari tanggal 15 Februari sampai dengan 31 Maret 2020. Pihak BPS berharap, para pejabat yang mengikuti Rapat Koordinasi ini berperan mengajak masyarakat untuk mengikuti Sensus Penduduk online (SPO). Kepala BPS Kabupaten Karangasem, Komang Bagus Pawastra mengungkapkan terkait tahap kedua, adalah kegiatan verifikasi dan pencacahan lapangan yang akan dilaksanakan pada tanggal 1 hingga 31 Juli 2020. Sebelum dilakukan pencacahan lapangan akan dilakukan verifikasi lapangan. Dikatakan Bagus Pawastra (2020), diharapkan jumlah penduduk suatu wilayah 
berdasarkan jenis kelamin, kelompok umur, pendidikan yang ditamatkan dicatat dengan baik. Dengan mengetahui kondisi tersebut pemerintah pusat mau pun daerah dapat memperoleh gambaran tentang kebutuhan wilayah.

Berdsarkan uraian latar belakang di atas, maka dapat dirumuskan permasalahan sebagai berikut:

1. Bagaimakah Pentingnya Administrasi Kependudukan Terkait Sensus Penduduk Secara One Linedi DesaPertima Kecamatan Karangasem Kabupaten Karangasem?

2. Apa saja kendala dan upaya pelaksanaan sensus online di Desa Pertima Kecamatan Karangasem Kabupaen Karangasem?

Pada penelitian ini, metode penelitian yang dilakukan adalah dengan melakukan wawancara kepada Kepala Desa di Desa Pertima Kecamatan Karangasem Kabupaten Karangasem, Kepala BPS Kabupaten Karangasem, selain itu juga dilakukan penelitian kepustakaan dengan membaca literatur yang berkaitan dengan sensus penduduk secara online, observasi dan penelitian lapangan, dimana penelitian dilakukan dengan terjun langsung ke Desa Pertima Kecamatan Karangasem Kabupaen Karangasem

\section{Pembahasan}

\section{Pentingnya Administrasi Kepend- udukan Terkait Sensus Penduduk Secara One Line}

\section{Kondisi Kependudukan Desa Pertima}

Pada tahun 1989, Desa pertima merupakan bagian dari Desa Bugbug, yang mewilayahi 17 ( tujuh belas ) Br. Dinas yang berada di 4 ( empat ) Desa Adat yaitu : Desa Adat Bugbug mewilayahi $8 \mathrm{Br}$. Dinas, Desa Adat Perasi mewilayahi 3 Br.Dinas, Desa Adat Timbrah mewilayahi 4 Br.Dinas, dan Desa Adat Asak mewilayahi 2 Br.Dinas. Nama Desa Pertima adalah merupakan pencairan dari Desa Adat yang disingkat, yang kepanjangannya Per $=$ Perasi, Tim = Timbrah, dan A = Asak. Disamping itu, kata Pertima mengandung kata yang sakral yaitu Pretima yang merupakan barang tak terhitung nilainya karena kesakralannya, yang merupakan perwujudan keyakinan Umat Hindu untuk mendekatkan diri kehadapan Tuhan Yang Maha Kuasa.

Adapun batasan desa pertima sebe- lah utara yaitu dengan Desa Bungaya, Sebelah Timur yaitu dengan Kelurahan Subagan, Sebelah Selatan yaitu dengan Laut Selat Lombok dan Sebelah Barat dengan Desa Bugbug dan Desa Tenganan Kecamatan Manggis.

Jumlah penduduk Desa Pertima berdasarkan hasil sensus pada tahun 2010, adalah sebanyak 5.806 jiwa, terdiri dari 2.903 jiwa penduduk laki-laki dan 2.903 jiwa penduduk perempuan, yang terdiri dari $1.656 \mathrm{KK}$.

Struktur penduduk menurut mata pencaharian menunjukkan bahwa sebagian besar penduduk menggantungkan sumber kehidupannya di sektor pertanian $(89,82 \%)$, sektor lain yang menonjol dalam penyerapan tenaga kerja adalah perdagangan $(1,92 . \%)$, sektor industri rumah tangga dan pengolahan $(1,23 \%)$, sektor jasa $(2,07 \%)$ dan sektor lainnya seperti pegawai negeri, karyawan swata dari berbagai sektor $(4,96 \%)$.

Kebudayaan Daerah Desa Pertima, tidak terlepas dan diwarnai oleh Agama Hindu dengan konsep "Tri Hita Kara- na" (hubungan yang selaras, seimbang dan serasi antara manusia dengan $\mathrm{Tu}$ - hannya, manusia dengan manusia dan manusia dengan lingkungannya).

Struktur perekonomian Desa Pertima, masih bercorak agraris yang menitik beratkan pada sektor pertanian. Hal ini didukung oleh penggunaan lahan pertanian masih mempunyai porsi yang terbesar sebanyak $80 \%$ dari total penggunaan lahan desa. Pada sektor ini komoditi yang menonjol sebagai hasil andalan adalah Jagung, ketela pohon dengan luas lahan pertanian adalah 60 ha dengan hasil per hektar adalah 350.000 .

Beberapa sektor ekonomi yang tergolong economic base dan menonjol di samping sektor pertanian adalah, perdagangan, industri rumah tangga dan pengolahan serta sektor pariwisata. Pada sektor industri rumah tangga dan pengolahan termasuk didalamnya adalah kerajinan ukir, percetaan ,pengolahan kayu , paras dan batako. 


\section{Pengertian administrasi Kepen- dudukan}

Administrasi Kependudukan adalah rangkaian kegiatan penataan dan penertiban dalam penerbitan dokumen dan Data Kependudukan melalui Pendaftaran Penduduk, Pencatatan Sipil, pengelolaan informasi Administrasi Kependudukan serta pendayagunaan hasilnya untuk pelayanan publik dan pembangunan sektor lain (Depdagri RI Dirjen Administrasi Kependudukan, 2008: 3).

Dalam peraturan pemerintah pada Undang-undang No. 23 Tahun 2006 tentang Administrasi Kependudukan yang dimaksud dengan Administrasi kependudukan adalah:

Administrasi Kependudukan adalah rangkaian kegiatan penataan dan penerbitan dokumen dan data kependudukan melalui program pendaftaran penduduk, pencatatan sipil, pengelolaan informasi administrasi kependudukan serta pendayagunaan hasilnya untuk pelayanan publik dan pembangunan sektor lain ". (UU No. 23 Tahun 2006: 4). Penduduk merupakan modal dasar dalam pembangunan, jumlah penduduk yang besar merupakan potensi pembangunan yang berarti suatu daerah memiliki Sumber Daya Manusia yang cukup.

\section{Sensus Penduduk Secara Online}

Sensus Penduduk Online merupakan salah satu tahap SP2020 dimana penduduk dapat mengisikan informasinya secara mandiri melalui web sensus.bps.go.id Data kependudukan yang akurat dan mutakhir merupakan dasar bagi pemerintah untuk membuat perencanaan di berbagai bidang pembangunan, mulai dari persoalan pendidikan, perekonomian, kesehatan, hingga program sosial. Selain itu, data kependudukan yang akurat menjadi pijakan pemerintah dalam merencanakan kebijakan yang tepat sasaran. "Sensus penduduk adalah hal penting bagi pemerintah, karena kebijakan pemerintah baik itu kebijakan pembangunan maupun kebijakan lainnya bersumber pada jumlah penduduk data statistik dan juga hasil sensus penduduk itu sendiri. Adapun rangkaian SP 2020 yakni SP Online berlangsung pada 15 Februari hingga 31 Maret 2020. Sementara Sensus Penduduk Wawancara dilakukan pada 1 hingga 31 Juli 2020 dan di ta- hap kedua dilakukan pencacahan sampel pada Juli 2021.SP online sendiri dilakukan dengan cara mengakses sensus.bps.go.id. Berikutnya, masyarakat memasukkan Nomor Induk Kependudukan (NIK) dan Nomor Kartu Keluarga (KK) dan klik 'Cek Keberadaan'. Setelah membuat password dan masuk. Terdapat 21 pertanyaan dasar seperti nama lengkap, alamat, pekerjaan, pendidikan, dan perumahan. Setelah menjawab pertanyaan terkait data keterangan individu dan perumahan, masyarakat dapat mengirimkan dan mencetak (unduh) bukti partisipasi dalam SP Online.

Cara mendaftar secara online sebagai berikut:

1) Masuk ke laman sensus.bps.go.id untuk masuk ke Sensus Penduduk Online 2020.

2) Masukkan Nomor Induk Kependudukan (NIK) pada KTP dan nomor Kartu Keluarga (KK).

3) Klik kotak kosong pada captcha, lalu klik Cek Keberadaan.

4) Jika pertama kali melakukan akses Sensus Penduduk Online, buat kata sandi dan pertanyaan keamanan, kemudian klik Buat Pasword. Kemudian masuk dengan memasukkan kata sandi yang telah dibuat.

5) Untuk meyakinkan dan tidak terjadi kesalahan, sebaiknya membaca panduan awal terlebih dulu sebelum $\mathrm{Mu}-$ lai Mengisi.

6) Pilih bahasa yang dikuasai Ikuti petunjuk dan jawab seluruh pertanyaan yang diberikan dengan jujur.

7) Pada halaman pertama, penduduk diminta mengisi alamat tinggal keluarga saat ini, seperti provinsi, kota, kabupaten, kecamatan, desa atau kelurahan, RT/RW, dan nomor rumah. Di halaman selanjutnya, mengisi keterangan kondisi tempat tinggal. Selanjutnya diminta mengisi data keluarga satu persatu, dimulai dari kepala keluarga, istri, anak, atau anggota lainnya. Kemudian mengisi data aktivitas sehari-hari.

8) Kemudian klik Kirim jika semua pertanyaan sudah terjawab. Unduh dan kirimkan bukti pengisian ke email pribadi yang sebelumnya sudah didaftarkan.

SP Online merupakan hal yang perta- 
ma kali digelar dalam sejarah Inndonesia. Sensus Penduduk ini menggunakan metode kombinasi dengan memanfaatkan data Dukcapil sebagai data dasar (prelist). SP 2020 menjalankan amanah Undang-undang No. 16 Tahun 1997 tentang Statistik serta rekomendasi PBB kepada seluruh negara untuk menyelenggarakan sensus minimal satu kali setiap 10 tahun. Hal ini menjadikan SP 2020 sebagai salah satu implementasi dari Perpnes No. 39 Tahun 2019 tentang Satu Data Indonesia dan Perpres No. 62 Tahun 2019 tentang Strategi Nasional Percepatan Administrasi Kependudukan untuk Pengembangan Statistik Hayati," Terdapat dua tujuan utama SP 2020 (menurut wawancara dengan Kepala Desa Pertima, yakni: menyediakan data jumlah, komposisi, distribusi, dan karakteristik penduduk Desa Pertima menurut de facto dan de jure menuju Satu Data Kependudukan Indonesia. Kedua, yakni menyediakan parameter demografi dan proyeksi penduduk (fertilitas, mortalitas, dan migrasi), serta karakteristik penduduk lainnya untuk keperluan proyeksi penduduk dan berbagai indikator Target Pembangunan Berkelanjutan (SDGs).

Adapun pentingnya administrasi kependudukan di Desa Pretima terkaitt dengan sensus online menurut Kepala BPS Kabupaten Karangasem, antara lain:

a. Tersedia data tunggal kependudukan yang akurat, terutama data dasar berupa jumlah, komposisi, distribusi, dan karakteristik penduduk di Desa Pertima. Data ini sangat penting untuk perencanaan dan pengambilan kebijakan di berbagai bidang.

b. Data kependudukan juga digunakan untuk mengantisipasi perubahan atau kebutuhan di masa mendatang. Di level individu, ketersediaan data yang akurat membantu warga Desa Pertima merasakan dampak nyata kebijakan tertentu, misalnya terkait layanan publik, fasilitas kesehatan, pemberian bantuan ketika terjadi bencana, atau perencanaan ketahanan pangan.

2 Kendala dan upaya dalam pelaksanaan sensus Online di Desa Pertima Kecamatan Karangasem Kabupaen Karangasem.

Tingkat partisipasi masyarakat Desa Pertima Kecamatan Karangasem Kabu- paten Karangasem untuk mengikuti Sensus Penduduk Online (SPO) masih rendah. Sampai awal Maret 2020 ini, masyarakat Desa Pertima yang sudah melakukan SPO sebanyak $950 \mathrm{KK}$.

Kepala Badan Pusat Statistik (BPS) Cabang Karangasem, I Komang Bagus Pawastra, Senin (2/3/2020), mengatakan,banyak kendala yang dihadapi oleh masyarakat dalam melakukan SPO. Salah satunya, kata Bagus Pawastra, terkendala jaringan internet terutama masyatakat di Desa Pertima. "Kendala mereka adalah jaringan internet, terutama masyarakat pedesaan,"

Komang Bagus Pawastra juga mengatakan, kendala lainya yang dihadapi oleh masyarakat yakni kemampuan literasidigital. Ia juga menyebut, dilapangan banyak orang tua yang tidak bisa mengoperasikan Hanphone berbasis android. Kalaupun ada anaknya, lebih tinggal di kota Denpasar. Ia juga menyebut kendala masih rendahnya masyarakat untuk melakukan SPO, karena masih ada hari raya keagamaan di Bali. Bahkan, tidak saja di masyarakat umum, di kalangan Aparatur Sipil Negara (ASN) dan tenaga kerja kontrak juga masih kisaran 35 persen. "Kalau ASN dan kontrak itu lebih karena masih disibukan hari raya Galungan dan Kuningan," ujarnya lagi.

Dikatakanya, untuk masyarakat yang belum melaksanakan SPO, BPS sendiri akan melaksanakan sensus secara manual setelah 31 Maret 2020 mendatang. SPO masih berlangsung sampai 31 Maret. Sedangkan, dalam sensus penduduk manual nanti pihaknya akan menerjunkan 607 petugas. "Kita siapkan 607 petugas yang siap ke masyarakat, tetapi kita berharap partisipasi masyarakat juga lebih aktif," pungkasnya.

Selain itu, permasalahan yang dihadapi yaitu tidak bisa login sensus penduduk 2020 secara online.

Dalam proses sensus secara online juga tidak sedikit masyarakat masih kebingungan, belum paham serta mendapatkan kendala dan bermasalah dengan sistem. Akan tetapi masalah-masalah dalampendaftaran tentunya dapat diatasi dengan solusi yang telah disediakan oleh BPS.

1. Apakah setiap anggota keluarga bisa mengisi sensus penduduk?

Sebagaimana yang dilansir oleh 
https://sensus.bps.go.id, bahwa seluruh anggota dalam daftar Kartu Keluarga (KK) dapat masuk dan mengisi Sensus Penduduk Online dengan menggunakan NIK mas- ingmasing dan Password yang sama.

2. Tidak dapat mengakses sensus pendudukan dengan NIK dan nomor KK Apabila menemukan masalah ini, maka dipersilakan menggunakan pasangan NIK dan KK dari anggota keluarga lain yang masih dalam satu KK. Jika memang tidak ada data, BPS akan mengunjungi keluarga tersebut dalam SP2020-Wawancara pada bulan Juli 2020.

3. Apakah bisa menambah anggota keluarga baru yang tercatat di dalam KK Setiap keluarga yang memiliki anggota keluarga baru namun belum tercatat dalam KK, maka dapat menambahkan anggota keluarga yang belum tercatat tersebut di kartu keluarga dengan catatan anggota keluarga baru tersebut tinggal bersama Bapak/Ibu.

4. Apakah bisa memperbaiki nama? Setiap anggota keluarga tidak bisa mengubah namanya. Karena NIK dan nama merupakan isian yang tidak dapat diubah.

5. Bagaimana bila anggota keluarga tidak muncul pada sistem sensus penduduk. Padahal ada di dalam KK? Apabila menemukan masalah ini, maka silakan masukan anggota keluarga tersebut pada halaman daftar anggota keluarga dan pastikan mengisi keterangan individunya secara lengkap.

6. Bagaimana jika data yang muncul di sensus penduduk adalah data KK yang lama, padahal sudah ada KK yang baru?

Susunan anggota keluarga yang tertera dalam Sensus Penduduk Online dapat mengikuti susunan anggotakeluarga pada KK sebelumnya. Silahkan tambahkan anggota keluarga yang belum ada serta sesuaikan status keberadaan dan alamat anggota keluarga yang ada dalam daftar.

7. Bagaimana cara mengetahui partisipasi sensus penduduk 2020 sudah berhasil?

Untuk mengetahui apakah pengisian sensus penduduk online sudah ber- hasil atau tidak, dapat di lihat pada halaman ringkasan yang akan muncul setelah mengisikan semua anggota keluarga. Pada halaman ini akan dimunculkan mana isian anggota keluarga yang masih ada kesalahan dan yang mana sudah benar. Jika semua isian sudah benar namun masih ada yang perlu diperbaiki, dapat mengklik tombol simpan. Namun jika dirasa sudah benar, dapat mengirim hasil Sensus Penduduk Online dengan mengklik tombol kirim. Selanjutnya dapat mendownload bukti pengisian Sensus Penduduk Online.

8. Apakah saat masuk ke web sensus kependudukan harus menggunakan NIK Kepala Keluarga?

Untuk mengisi Sensus Penduduk Online dapat menggunakan NIK yang terdaftar dalam Kartu Keluarga, tidak harus menggunakan NIK Kepala Keluarga.

9. Apakah bisa mengedit kembali data sensus yang sudah terkirim?

Bagi anda yang mengedit kembali, maka dibolehkan. Pengguna dapat login kembali dengan mengisikan NIK, KK dan password yang dibuat sebelumnya. Isian pertanyaan pada Sensus Penduduk Online dapat dilanjutkan/disesuaikan lagi selama belum mengklik tombol kirim pada halaman terakhir kuesioner. Jika sudah mengklik tombol kirim, maka isian dianggap final dan tidak dapat melakukan perubahan pada data yang sudah diisi.

\section{Simpulan dan Saran}

\section{Simpulan}

1) Pentingnya Administrasi Kependudukan Terkait Sensus Penduduk Secara One Linedi DesaPertima Kecamatan Karangasem Kabupaten Karangasem adalah:

a. Tersedia data tunggal kependudukan yang akurat, terutama data dasar berupa jumlah, komposisi, distribusi, dan karakteristik penduduk di Desa Pertima. Data ini sangat penting untuk perencanaan dan pengambilan kebijakan diberbagai bidang.

b. Data kependudukan juga digunakan untuk mengantisipasi perubahan 
atau kebutuhan di masa mendatang. Di level individu, ketersediaan data yang akurat membantu warga Desa Pertima merasakan dampak nyata kebijakan tertentu, misalnya terkait layanan publik, fasilitas kesehatan, pemberian bantuan ketika terjadi bencana, atau perencanaan ketahanan pangan

2) Kendala dan upaya pelaksanaan sensus online di Desa Pertima Kecamatan Karangasem Kabupaen Karangasem

Adapun kendala yang dihadapi dalam pendataan penduduk adalah sulitnya login sensus penduduk secara online, kendala jaringan internet, masyarakat yang masih awam teknologi. Untuk mengatasi dilakukan dengan memberi sosialisasi kepada aparat desa agar bisa memandu warganya untuk sensus secara online. Memanfaatkan handphone yang mempunyai fasilitas androi sehingga bisa mengakses internet dengan cepat.

\section{Saran}

Demi tercapainya tujuan penyatuan data kependudukan yang akurat, maka diperlukan dukungan semua pihak, baik masyarakat maupun aparat pemerintah, khususnya di desa, dimana masyarakat masih banyak yang awam teknologi, perlu disosialisasikan cara-cara pendaftaran penduduk secara online. Di samping itu, kelian dinas di masing-masing banjar hendaknya bisa mensosialisasikan dan mengarahkan masyarakatnya agar bisa melaksanakan sensus penduduk secara online guna menunjang pembangunan nasional.

\section{DAFTAR PUSTAKA}

Ka ranga se m kab.go.i d/index.php/ baca-berita/7407/BUPATI-MAS-SUMATRI- BUKA-RAPAT- KOORDINASI-PELAKSANAAN-SENSUS-PENDUDUK-2020

Depdagri RI Dirjen Administrasi Kependudukan, 2008

https://pertimakarangasem.wordpress. com/kontak/ diakses tanggal 2 Juli 2020.

sensus.bps.go.id/cek

Undang-undang No. 23 Tahun 2006 tentang Administrasi Kependudukan

Undang-undang No. 16 Tahun 1997 tentang Statistik 